\title{
Extraction and electrochemical fingerprinting of total flavonoids from Hovenia spp.
}

\author{
Chiyu Ge, Junli Zhang*, Mengshuang Wang
}

School of Pharmacy, Jiangsu Food and Pharmaceutical Science College, Huai'an, 223005, Jiangsu, China

"E-mail: gechiyu2020@163.com

Received: 4 September 2021 / Accepted: 9 October 2021 / Published: 10 November 2021

The effective components of medicinal and edible plant are an important raw material for biological pharmacy and health food, thus flavonoids have become a research focus in biomedical field. Hovenia spp. is rich in flavonoids with a number of pharmacological effects. In this work, ultrasonic assisted and ethanol reflux method was first to be adopted to extract the total flavonoids of Hovenia spp. The effects of solvent concentration, liquid-to-solid ratio, ultrasonic/ethanol reflux temperature and extraction time in the extraction process were investigated. Afterwards, the electrochemical fingerprinting of total flavonoids were recorded. Three factors extracted from PCA analysis can reach an interpretation rate of $98 \%$. The identification of each species can be achieved by locating the hot area of the 2D density pattern, which is much easier compared with using electrochemical fingerprinting.

Keywords: Electrochemical fingerprint; Total flavonoids; Hovenia; Extraction; PCA analysis

\section{FULL TEXT}

(C) 2021 The Authors. Published by ESG (www.electrochemsci.org). This article is an open access article distributed under the terms and conditions of the Creative Commons Attribution license (http://creativecommons.org/licenses/by/4.0/). 